\title{
Characteristics and Cardiomyogenic Potential of Rat Fetal Cardiac Progenitor Cells at Different Developmental Stage
}

\author{
Tung Nguyen Thanh ${ }^{1} \cdot$ Him Cha Shin ${ }^{2} \cdot$ Hwal Ran Kim ${ }^{3}$ So Ra Park ${ }^{2}$. \\ Jiyoung $\mathrm{Kim}^{4} \cdot$ Byung Hyune Choi ${ }^{1}$
}

Received: 16 March 2016/Revised: 19 April 2016/Accepted: 19 April 2016/Published online: 6 March 2017

(c) The Korean Tissue Engineering and Regenerative Medicine Society and Springer Science+Business Media Dordrecht 2017

\begin{abstract}
In recent years, several kinds of cardiac progenitor cells have been identified and isolated from heart tissue. These cells showed differentiation potential into cardiomyocytes, smooth muscle cells, and endothelial cells in vitro and in vivo. Morphogenetic events are tightly regulated during development to determine cell destiny and reshape the embryonic lineage. In this study, we directly compared the characteristics of rat fetal cardiac progenitor cells (rFCPCs) isolated from the chamber formation stage at embryonic day 12 (E12) and at the septation stage of E15. Both kinds of rFCPCs expressed mesenchymal stem cell markers (CD105, CD73, and CD29) but not CD34 and CD45. The E12 rFCPCs expressed a high level of Oct 4 compared to E15 until passage 5 and showed a steep decline of Nkx2.5 expression at passage 5. However, Nkx2.5 expression at E15 was maintained until passage 5 and Oct4 expression slightly increased at passage 5. We also detected an intense staining for Oct4 antibody in E12 heart tissue sections. The average doubling time of the E12 rFCPCs from passage 3 to passage 15 was about 5 hours longer than E15. These cells could also be induced into cardiomyocytes expressing $\alpha-\mathrm{MHC}, \mathrm{cTnT}, \mathrm{cTnC}$, and $\mathrm{Cx} 43$ under cardiomyogenic culture conditions and rFCPCs at E15 showed more intense staining of $\alpha$-MHC than cells at E12 by immunocytochemistry. Taken together, our results show that developmental differences between E12 and E15 may influence their properties and differentiation. Furthermore those differences should be considered when deciding on the optimal cell source for cell replacement therapy in cardiovascular regeneration.
\end{abstract}

Keywords Rat fetal cardiac progenitor cells · Gestation age $\cdot$ Cardiomyogenic differentiation - Cardiovascular regeneration

Jiyoung Kim

jkim.kolleen@hanmail.net

$\bowtie$ Byung Hyune Choi

bryan@inha.ac.kr

1 Department of Biomedical Sciences, Inha University College of Medicine, 100 Inharo, Nam-gu, Incheon 22212, Korea

2 Department of Physiology, Inha University College of Medicine, 100 Inharo, Nam-gu, Incheon 22212, Korea

3 Department of Molecular Science and Technology, Ajou University, 206 Worldcup-ro, Yeongtong-gu, Suwon 16499, Korea

4 Inha Research Institute for Medical Sciences, Inha University College of Medicine, 100 Inharo, Nam-gu, Incheon 22212, Korea

\section{Introduction}

Heart disease in humans, which develops after myocardial infarction (MI) or chronic hypertension, is a major cause of death in developed countries and no current therapy is able to reverse the implacable worsening of cardiac function. Cardiac transplantation is an ideal and alternative treatment for patients but there are two major limitations, one of which is the shortage of donor tissues available for transplantation and the other is the use of immunosuppressive drugs. Therefore, new strategies investigating cardiac regeneration are being explored as an alternative and include the following: (1) paracrine factors that can mobilized resident cardiac progenitor cells and promote 
proliferation and differentiation into mature cardiomyocytes (2) stem cell transplantation and (3) transplantation of engineered cardiac tissues [1, 2]. Adult stem cells derived from various tissue sources have been extensively explored for their therapeutic efficacy in cardiac regeneration. There have been already several ongoing clinical trials for cardiac repair whereby bone marrow derived cells or peripheral blood-derived endothelial progenitor cells were transplanted via intra-coronary cell infusion or direct intra-myocardial injection inpatients after MI [3, 4]. However, the results from these studies are still uncertain since transplanted cells engraft poorly in cardiac tissue and even then, their cardiomyogenic potential remains contentious [5].

Cardomyocytes were long considered post mitotic terminally differentiated cells that underwent cellular hypertrophy [6]. However, the presence of resident stem cells in the human adult heart have been reported [7, 8]. Cardiac stem cells originated from the pro-epicardium during development and exhibit distinctive properties related to their tissue origin [9], and are more efficient in the expression of cardiovascular markers and their differentiation into the cells of the cardiovascular lineage compared to BM-MSCs because they might be already committed to the cardiovascular lineages $[10,11]$. However, cardiac stem cells isolated from an adult heart would have several problems. They undergo replicative senescence during ex vivo expansion and the source of cardiac stem cells is via an endomyocardial biopsy, which is an invasive procedure and the yield of the cells is also very low. Fetal tissue derived stem cells have a greater proliferative capacity and differentiation potential compare with adult stem cells $[12,13]$ and they also have a low risk of tumorigenic and immunogenic problems [14, 15]. Fetal stem cells have already been isolated from bone marrow, lung, liver, spleen, brain [16, 17]. In fetal heart tissue, human cardiac progenitor cells have been isolated and shown to be multi-potential to mesodermal lineage cells and exhibit a significantly higher proliferation rate than adult cardiac progenitor cells [18]. Human fetal cardiovascular progenitor cells expressing $\mathrm{Nkx} 2.5$ have been reported to express the mesenchymal stem cells (MSCs) markers [19]. Rat fetal cardiac MSCs were identified to express common MSCs markers and embryonic stem cells (ESCs) markers, and also exhibit telomerase activity $[20,21]$. In mice, it has been examined that exogenous cardiomyocytes structurally and functionally integrate into the host myocardium using fetal or neonatal cardiomyocytes [22]. These results have suggested that fetal cardiac progenitor cells represented a suitable source for cell replacement therapy to repair the injured myocardium.

While the presence of fetal cardiac stem cells seems promising, several questions still remain. Fetal stem/ progenitor cells may have a different characteristics and potentials with developmental stages, which will be important to investigate cell-based therapies. For example, Nkx2.5 positive human cardiac progenitor cells at 4 weeks of gestation expressed Oct 4 proteins and cardiac progenitor cells at 12 weeks expressed $\mathrm{Nkx} 2.5, \mathrm{CD} 73, \mathrm{CD} 90$, and CD105 [19]. van Vliet et al. [18] showed that fetal and adult cardiac progenitor cells have distinct preferences to differentiate into mesodermal lineages. Under pro-angiogenic conditions, fetal cells at 13-17 weeks of gestation formed more endothelial but less smooth muscle cells than adult cells. Fetal cells can also develop towards adipocytes, whereas neither fetal nor adult cells showed significant osteogenic differentiation.

Many studies have been reported on the isolation and characterization of cardiac stem/progenitor cells from adult hearts. However, there is little information about these cells derived from embryonic hearts. This study investigated fetal heart-derived stem/progenitor cells (rFCPC) at E12 and E15 after gestation. The developmental stages correspond to rat E12 and E15, which represent chamber formation stage and septation formation stage [23]. By rat E12, the heart had acquired well-defined chambers but were still tubes and then the chambers were separated as a result of separation from E13.5 to birth [23, 24]. Signals and morphogenetic events are tightly regulated during embryogenesis because of determination of cell destiny and reshaping of the embryonic lineage but the observed morphological changes during heart development may be a tenuous argument to decide the actual cell properties. Little is known regarding the similarities and differences of fetal cells under the embryonic developmental stage and there is no literature to determine the direct comparison about properties of fetal cardiac stem/progenitor cells with the developmental stage. In this study, we investigated the characteristics and cardiomyogenic potential of cardiac progenitor cells isolated from a fetus at two different developmental stages and compared the pluripotency markers and cardiomyogenic potential of fetal cardiac progenitor cells at E12 and E15 using a rat model. Therefore, we evaluated the suitability of fetal cardiac stem/progenitor cells at the developmental stage as a therapeutic cell source.

\section{Materials and methods}

\subsection{Rat fetal cardiac progenitor cell isolation and culture}

Pregnant Sprague-Dawley rats were purchased from Orient Bio Inc. (Seongnam, Korea). All animals used in this study were treated in accordance with the INHA University 
Institutional Animal Care and Use Committee (INHAIACUC approval number: 121120-168) on their ethical procedures and scientific care. After induction of anesthesia with $3 \%$ isoflurane, embryos were collected at 12 and 15 days post coitus ( $\mathrm{dpc}$ ) from pregnant rats to isolate fetal cardiac progenitor cells (rFCPCs). Remodelling heart E12 and four-chambered heart E15 were minced and digested with $0.2 \%$ collagenase type 2 (Worthington Biochemical Corp, Lakewood, NJ, USA) in Dulbecco's phosphate-buffered saline (DPBS) (GIBCO BRL, Grand Island, NY, USA) for $90 \mathrm{~min}$ at $37{ }^{\circ} \mathrm{C}$. Cells suspensions were cultured in Dulbecco's modified eagle's medium (DMEM)/Ham's F12 (1:1) supplemented with $20 \mathrm{ug} / \mathrm{L}$ epidermal growth factor (EGF) (Peprotech, Rocky Hill, NJ, USA), $10 \mathrm{ug} / \mathrm{L}$ basic fibroblast growth factor (bFGF) (Peprotech), $10 \%$ fetal bovine serum (FBS) (GIBCO BRL), and penicillinstreptomycin (GIBCO BRL) at $5 \% \mathrm{CO}_{2}, 37{ }^{\circ} \mathrm{C}$. Medium was changed twice a week. Cumulative population doubling at each subculture was calculated by using the formula $2^{\mathrm{X}}=N_{H} / N_{I}$, where $N_{I}=$ the inoculum cell number, $N_{H}=$ cell harvest number at confluence $(>80 \%)$, and $X=$ population doublings [25].

\subsection{Colony-forming unit-fibroblast (CFU-F)}

Cells at passage 2 (p2) were seeded at a final concentration of 150 cells/100 $\mathrm{mm}$ petri dish (Nunc, Rochester, NY, USA) in growth medium. The medium was changed every 2 or 3 days. After 14 days from culture, cells were fixed with $4 \%$ paraformaldehyde for $15 \mathrm{~min}$, and stained with $1 \%$ crystal-violet solution. Colonies were considered as clusters of more than 32 cells.

\subsection{RNA isolation and reverse transcription- polymerase chain reaction (RT-PCR)}

Total RNA was extracted from cells using Trizol (SigmaAldrich, St. Louis, MO, USA) as described by the manufacturer's instructions. The purity of the RNA was assessed by determining the ratio of absorbance at $260 \mathrm{~nm}$ to that at $280 \mathrm{~nm}$ (>1.8). Reverse-transcription polymerase chain reaction (RT-PCR) was performed using a GeneAmp PCR system 2400 (PerkinElmer Life and Analytical Sciences, Boston, MA, USA). Subsequent PCR reactions were performed using cDNA, primer pairs (Table 1), and HiPi PCR Premix (ELPis Biotech, Korea) according to the manufacturer's instructions. Glyceraldehyde 3-phosphate dehydrogenase (GAPDH) was used as an internal control.

\subsection{Flow cytometric analysis}

After trypsinization, detached cells were resuspended and then incubated with primary antibodies for 1 hour at $4^{\circ} \mathrm{C}$.
For CD105 and CD73 staining, fluorescein isothiocyanate (FITC)-conjugated secondary antibody was used for labeling. After washing, cells were analyzed on a FACS Calibur flow cytometer equipped with Cell Quest software (BD Biosciences, Franklin Lakes, NJ, USA). Monoclonal antibodies for flow cytometric analysis were purchased from the following companies: CD105, CD73, and CD45 (BD Biosciences); CD34 (Santa Cruz Biotech, Santa Cruz, CA, USA).

\subsection{Immunocytochemistry}

After culture in Lab-Tek chamber slides (Nunc), rFCPCs were fixed with $4 \%$ paraformaldehyde for $15 \mathrm{~min}$ at room temperature (RT). Cells were washed with PBS and then permeabilized with $0.25 \%$ Triton X-100 in PBS (PBST) for $10 \mathrm{~min}$ at RT. The slides were incubated in a blocking solution, consisting of $2 \%$ bovine serum albumin (BSA) in PBST for $60 \mathrm{~min}$ at RT. Between each step, cells were washed with PBST. Cells were then incubated with one of the following rabbit polyclonal antibodies: rabbit anti-Oct4 (1:100) (Abcam, Cambridge, MA, USA), rabbit anti-Sox2 (1:1000) (Abcam), rabbit anti-connexin 43 (CX43; 1:100) (Sigma-Aldrich), or with mouse monoclonal anti-heavy chain cardiac myosin (1:100) (Abcam). The slides were incubated with the primary antibody in PBST containing $1 \% \mathrm{BSA}$ for $1 \mathrm{~h}$ at room temperature (RT). After washing with PBST, cells on slides were labeled with FITC conjugated goat anti-rabbit secondary antibody (1:100) (Millipore, Billerica, MA, USA) or rhodamine conjugated donkey anti-mouse secondary antibody (1:100) (Jackson Immuno Research, West Grove, PA, USA) for $1 \mathrm{~h}$ at RT in the dark. Cells were then washed with PBST for $15 \mathrm{~min}$. Finally, cover slips were mounted onto glass slides with the Vectashield mounting medium containing DAPI (Vector laboratories, Burlingame, CA, USA). Cells were photographed under an axioplan2 epifluorescence microscope (Carl Zeiss, Oberkochen, Germany). Confocal pictures were taken with a confocal microscope (LSM 510; Carl Zeiss).

\subsection{Immunohistochemistry}

Rat fetus was removed from pregnant female at embryonic day 12 and 15 . Fetus tissue was fixed overnight at $4^{\circ} \mathrm{C}$ in $4 \%$ paraformaldehyde, embedded paraffin, and cut into $3-\mu \mathrm{m}$ sections followed by permeabilization with $1 \%$ Triton $\mathrm{X}-100$ in PBS for $10 \mathrm{~min}$. For antigen retrieval, tissue sections immersed in $10 \mathrm{Mm}$ citrate buffer ( $\mathrm{pH}$ 6.0) were placed in a microwave for $20 \mathrm{~min}$. Endogenous peroxidase activity was inactivated with $3 \%$ hydrogen peroxide for $15 \mathrm{~min}$ at RT. The sections were incubated in a blocking solution, consisting of $2.5 \%$ horse serum for $30 \mathrm{~min}$ at RT. 
Table 1 Primers used in the present study

\begin{tabular}{|c|c|c|c|c|}
\hline Gene & Primer sequence $\left(5^{\prime}-3^{\prime}\right)$ & Annealing temperature & Size & Accession number \\
\hline Oct4 & $\begin{array}{l}\text { AGTCCCTAGGTGAGTCGTCC } \\
\text { CAGAGTCTCCACGCCAACTT }\end{array}$ & 58 & 322 & NM_001009178 \\
\hline Nanog & $\begin{array}{l}\text { CGGTGGAGTATCCCAGCATC } \\
\text { CAAGGCTTGCGGGGTACTAA }\end{array}$ & 58 & 317 & NM_001100781 \\
\hline Sox 2 & $\begin{array}{l}\text { CATGAAGGAGCACCCGGATT } \\
\text { AGCCGTTCATGTAGGTCTGC }\end{array}$ & 58 & 356 & NM_001109181 \\
\hline NKX2.5 & $\begin{array}{l}\text { ACCCTCGGGCGGATAAGAA } \\
\text { GACAGGTACCGCTGTTGCTTGA }\end{array}$ & 59 & 178 & NM_053651 \\
\hline$\alpha-\mathrm{MHC}$ & $\begin{array}{l}\text { GGAGCTCACCTACCAGACAGA } \\
\text { CTCAGGGCTTCACAGGCATCC }\end{array}$ & 59 & 308 & NM_017240 \\
\hline $\mathrm{cTnT}$ & $\begin{array}{l}\text { GAACAGCAGCGTATTCGCAA } \\
\text { GCCTTCTCTCTCAGCTGGTC }\end{array}$ & 58 & 290 & NM_012676 \\
\hline GAPDH & CTCATGACCACAGTCCATGC & 58 & 155 & NM_017008 \\
\hline
\end{tabular}

After washing, sections were incubated with rabbit antiOct4 polyclonal antibodies (1:100) (Abcam) or rabbit antiSox2 polyclonal antibodies (1:100) (Abcam) for 1 hour at RT. After washing with PBST, the slides were then incubated with horseradish-peroxidase-conjugated secondary antibodies (Vector Laboratories) for $40 \mathrm{~min}$ at RT. Immunoactivity was detected by using a peroxidase substrate kit (Vector Laboratories) with 3,3'-diaminobenzidine (DAB). Counterstaining was done with Mayer's hematoxylin solution (Sigma-Aldrich). Imaging was visualized by an axioplan2 epifluorescence microscope.

\subsection{Differentiation of rFCPCs into cardimyocytes}

Cells at passage 4-5 were seeded onto 6-well culture plates at 10,000 cells per well in growth medium. After $40-50 \%$ confluence, cells were stimulated with $10 \mu \mathrm{M}$ 5-Azacitidine (AZA) (Sigma-Aldrich) on a serum free medium. After induction for 3 days, they were then cultured in various differentiation media consisting of $1 \mu \mathrm{M}$ dexamethasone (DEX) (Sigma-Aldrich), $1 \mathrm{ng} / \mathrm{mL}$ transforming growth factor-beta1 (TGF- $\beta 1$ ) (Peprotech), or DEX + TGF $\beta 1$ for 3 weeks. Media were changed twice a week.

\subsection{Western blotting}

Cells induced into cardiomyocytes were rinsed with ice-cold PBS and treated with ice-cold radio immunoprecipitation assay buffer (RIPA assay buffer) (Sigma-Aldrich) containing a protease inhibitor cocktail (Sigma-Aldrich) for $30 \mathrm{~min}$ with gentle agitation. Protein concentration was quantified using the Bradford protein assay kit (Bio-Rad, Hercules, CA, USA). Thirty micrograms of protein lysate were separated on sodium dodecyl sulfate (SDS)-10\% polyacrylamide gels, transferred onto polyvinylidene fluoride (PVDF) membranes, blocked with 5\% nonfat dry milk (Bio-Rad) in
Tris-buffered saline with Tween 20 (TBST; $10 \mathrm{mM}$ Tris$\mathrm{HCl}, \mathrm{pH} 7.6,150 \mathrm{mM} \mathrm{NaCl}$, and $0.05 \%$ Tween20) for 1 hour at RT. Primary antibodies were diluted in blocking buffer and incubated with the membrane overnight at $4{ }^{\circ} \mathrm{C}$ : alpha-heavy chain cardiac myosin (MHC, 1:250) (Abcam) and cardiac troponin C (cTnC, 1:200) (Santa Cruz Biotech). Beta-actin ( $\beta$-actin, 1:1000) (Santa Cruz Biotech) was used as an internal control. Membranes were washed and incubated with either peroxidase labeled anti-mouse antibody (1:10,000) (Thermo Scientific, Rockford, IL, USA), or antirabbit antibody $(1: 10,000)$ (Thermo Scientific), in blocking buffer $1 \mathrm{hr}$ at RT. Membranes were developed using a chemiluminescence assay kit (SuperSignal West Femto Maximum Sensitivity Substrate, Thermo Scientific). Protein expression was quantified relative to $\beta$-actin expression.

\subsection{Statistical analysis}

All data were presented as means \pm standard deviation. All experiments were performed three times. Statistical analysis was analyzed by one-way analysis of variance (ANOVA) followed by a Tukey HSD test using PASW statistics version 18.0 (SPSS Inc., Chicago, IL, USA). A $p$ value $<0.05$ was considered to be statistically significant.

\section{Results}

\subsection{Expression pattern of pluripotent stem cell marker by fetal tissues}

We examined the expression of Sox 2 and Oct4, a wellknown transcription factor that plays a critical role in the self-renewal and pluripotency of stem cells. The expression of Oct4 was detected in brain, liver, skin, or heart of E12 and E15 (Fig. 1A, B). For Sox2, those tissues exhibited two 
different patterns at E12 and E15. Brain tissue showed very intense staining with the antibodies against the Sox2, but heart, liver, and skin tissues exhibited moderated staining intensity. In the developmental stage, the heart at E12 was defined as the chamber formation stage, but was still a tube, and a four-chambered heart was formed from E15. Oct4 expression in heart tissue was decreased during development from E12 to E15, yet, Sox2 expression was slightly decreased during the development in E12 and E15.

\subsection{Morphology and ex vivo expansion of rFCPCs}

After the first subculture, plastic-adherent rFCPCs exhibited uniform and fibroblastic morphology. rFCPCs at E12 and E15, fibroblast-like cells, closely resembled MSC but the morphology of E12 and E15 were not entirely same, as shown in Fig. 2A. This morphology of rFCPCs persisted throughout the culture period before they reached senescence. Doubling time was calculated according to the period of culture to compare proliferation capacity of rFCPCs of E12 and E15. Average doubling time from passages $3-15$ was $28.7 \pm 2.4$ and $23.6 \pm 5.5$ hours, respectively (Fig. 2B).

To determine the self-renewal capacity, CFU-F assay was performed using the cells of E12 and E15 at passage 3 (Fig. 2C). rFCPCs derived from E12 formed colonies of $26.3 \pm 3.3$ which contained of colonies $15.3 \pm 1.5$ more than a diameter $3 \mathrm{~mm}$. Meanwhile, rFCPCs derived from
A
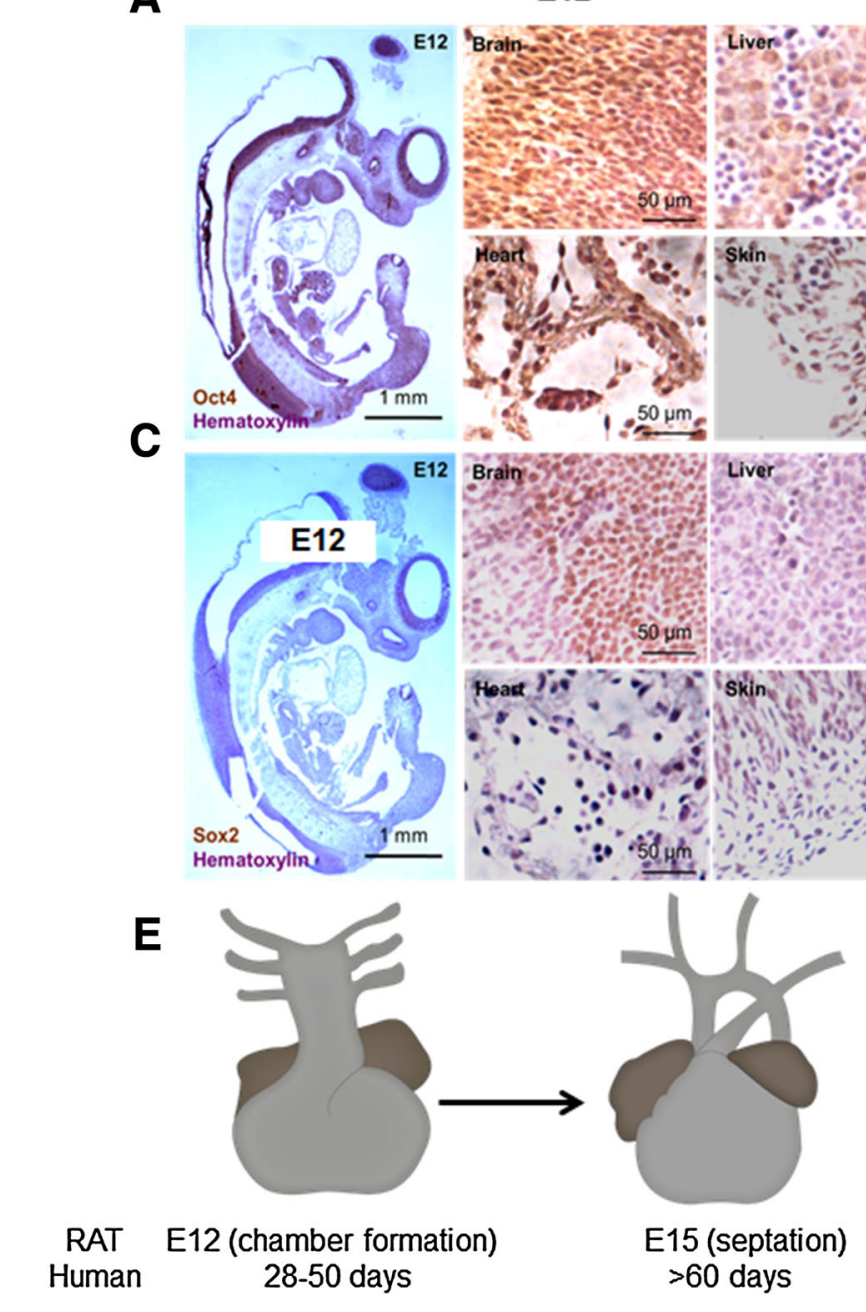

E12

Fig. 1 Oct4 and Sox 2 expression in rat embryos at E12 and E15 from gestation. Embryos were collected from pregnant SD rat at E12 (chamber formation stage) and E15 (septation stage) and protein localization of Oct 4 and Sox 2 was analyzed using immunohistochemistry after sagittal section. A Oct 4 protein expression in embryo of E12, B Oct4 protein expression in embryo of E15, C Sox2 protein
B

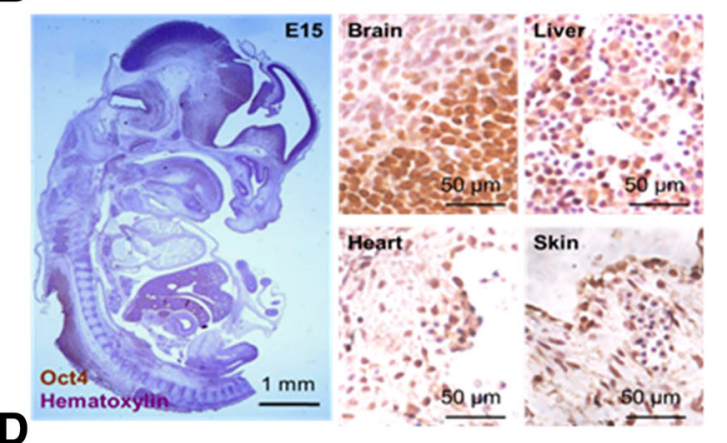

D

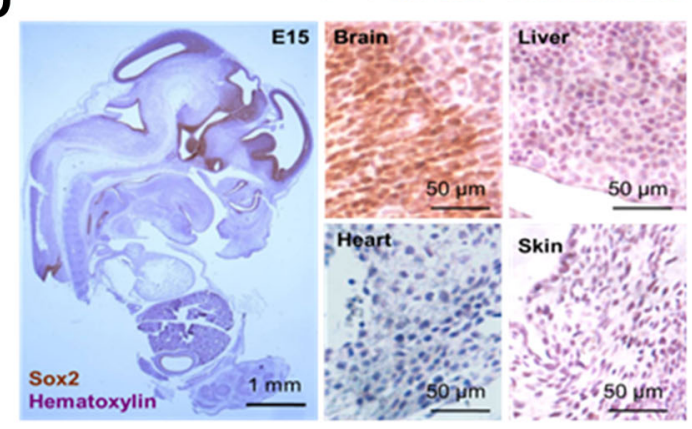

expression in embryo of E12, D Sox2 protein expression in embryo of E15, E Cardiac development stage. The septation of the atria and ventricles, and remodeling of the outflow tract to form the aorta and the pulmonary artery (High and Epstein 2008). Oct4 was expressed in brain, liver, heart, and skin of E12 and E15 embryos. Sox 2 was intensively expressed in brain of E12 and E15 embryos 
A

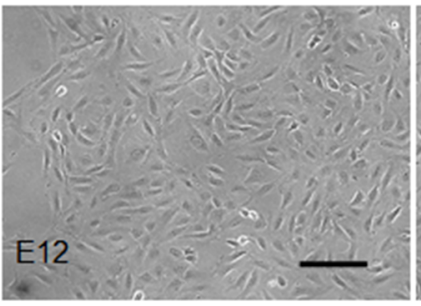

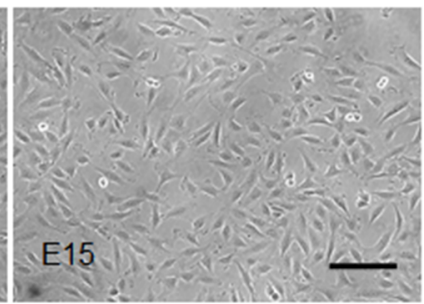

C
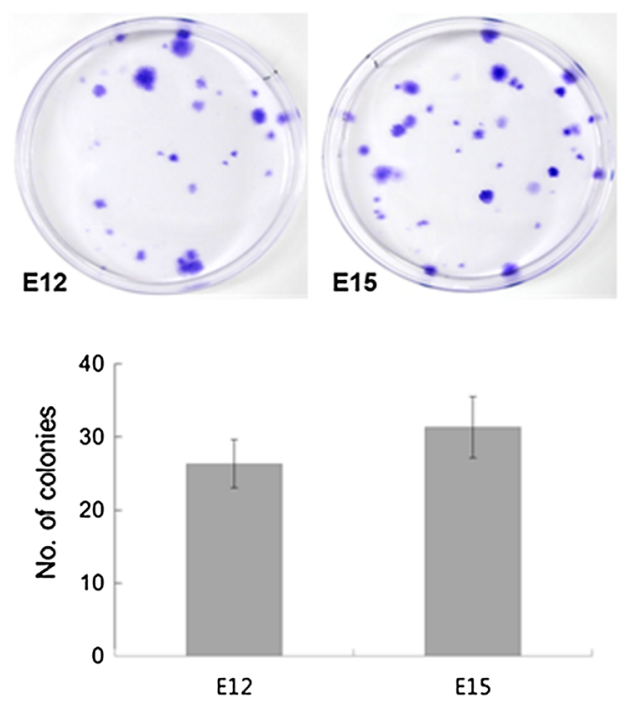

B

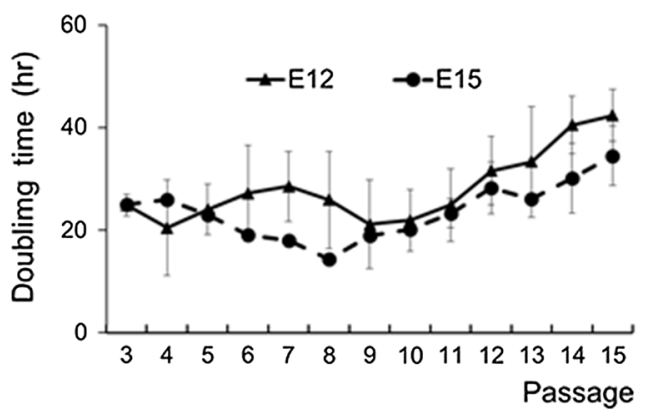

Fig. 2 Morphology and doubling time of rFCPCs during ex vivo expansion. A Morphology of rFCPCs of E12 and E15 at passage 3, B doubling time of rFCPCs of E12 and E15, C CFU assay

E15 formed colonies of $31.3 \pm 4.2$ which contained of colonies of $17.3 \pm 3.1$ more than a diameter of $3 \mathrm{~mm}$ (There was no significant difference between the two groups).

\subsection{Imunophenotype of rFCPCs}

Analysis of cell surface molecules of rFCPC at p1, p5 and p10 was performed using flow cytometry. The cells of E12 at passage 1 were strongly positive for CD105 (99.9\%), CD73 (99.9\%), and CD29 (88.3\%). The cells of E15, like E12, were strongly positive for CD105 (96.4\%) and CD73 (95.3\%), positive for CD29 (87.6\%). These patterns of MSCs makers were maintained until passage 10 of E12 and E15. All groups of rFCPCs were negative for CD34, CD45 (leukocyte marker), and c-kit, therefore, no significant difference was observed between E12 and E15 at p1, p5 and p10 (Fig. 3).

\subsection{Stem cell properties of rFCPCs}

The results of RT-PCR analysis of selected stemness genes showed that rFCPCs from E12 and E15 exhibited different expression patterns during ex vivo expansion (Fig. 4A). rFCPCs at both E12 and E15 expressed pluripotent stem cell genes of Oct 4 and Nanog. Conversely, the Sox 2 gene was not expressed in passage 1 and 5. E12 rFCPCs showed higher expression levels of Oct 4 than E15 rFCPCs at passage 1 and 5. For the Nanog gene, there were no differences between E12 and E15. The Nkx2.5 gene, cardiomyogenic demonstrated that E12 and E15 rFCPCs contained a subpopulation of cells capable of generating new colonies from single cells. Scale bar 200 um

progenitor cell marker, in E12 was strongly expressed at passage 1 and steeply decreased at passage 5 and $\mathrm{Nkx} 2.5$ gene expression at E15 was maintained until passage 5 . The Tbx 5 and GATA4 gene, early cardiac developmental gene, was slightly detected in primary cells but not detected in cells in passage 1 and 5 (data not shown).

Immunocytochemical staining demonstrated that rFCPCs from the third passage of E12 and E15 showed intense staining with the antibodies against the Oct4. However, rFCPCs did not stain with antibodies against Sox2 (Fig. 4B, C). These results were similar to those of immunohistochemistry. Oct 4 and Sox 2 expression patterns of rFCPCs might correlate with the undifferentiated cell properties and cell commitment.

\subsection{Cardiomyogenic potential of rFCPCs}

To induce cardiomyogenic differentiation, rFCPCs were stimulated by $5^{\prime}$-azacytidine and then cultivated in differentiation medium containing dexamethasone (D) or TGF$\beta 1$ (T) alone or in combination (DT) for 3 weeks. Fiveazacytidine, a DNA demethylating agent, is known to affect gene expression profiles, and changes in DNA methylation, histone acetylation and activated-ERK signaling status lead to cardiac differentiation [26]. Dexamethasone and TGF- $\beta 1$ are known to enhance in vitro cardiomyogenic differentiation [26, 27].

Gene expression of $\mathrm{Nkx} 2.5$, cardiac progenitor cell marker, was higher in the control group than all groups of differentiation at E12 rFCPCs, yet, E15 rFCPCs was 
E12

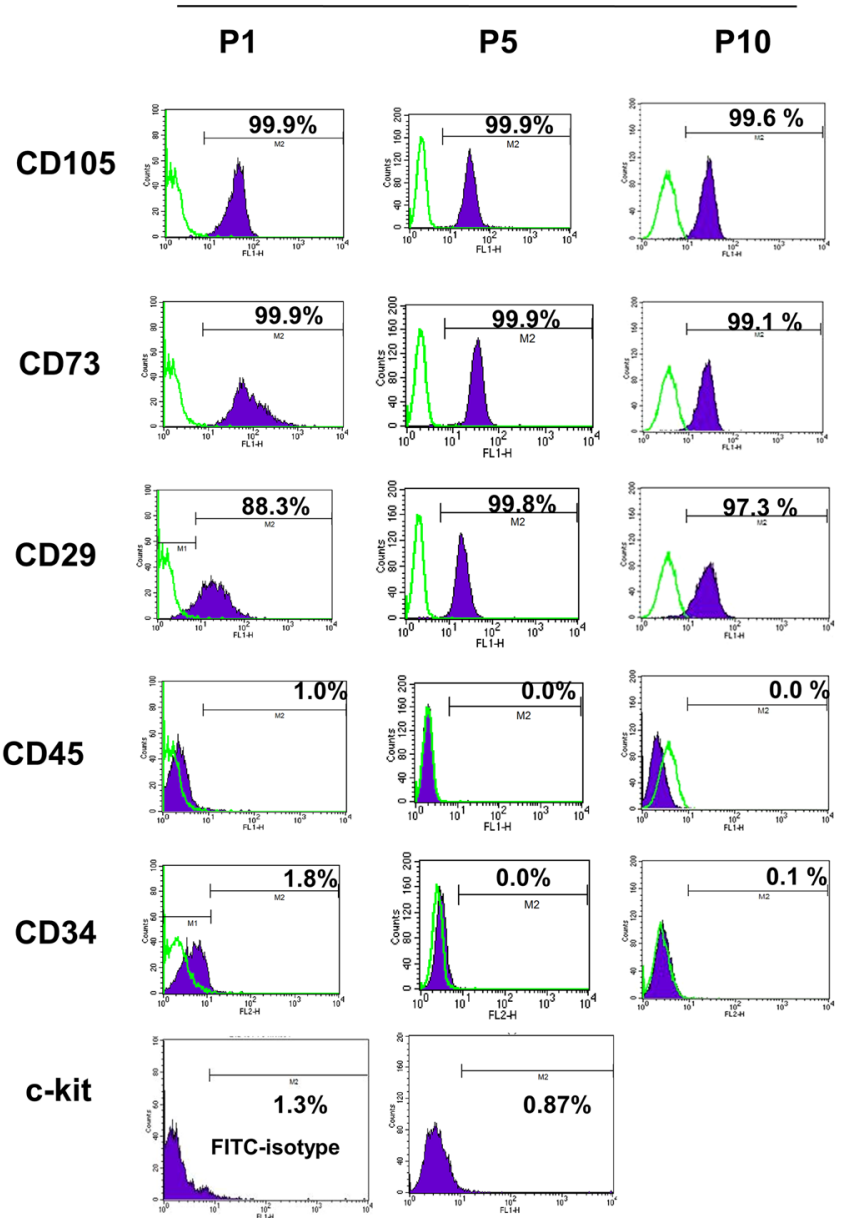

E15
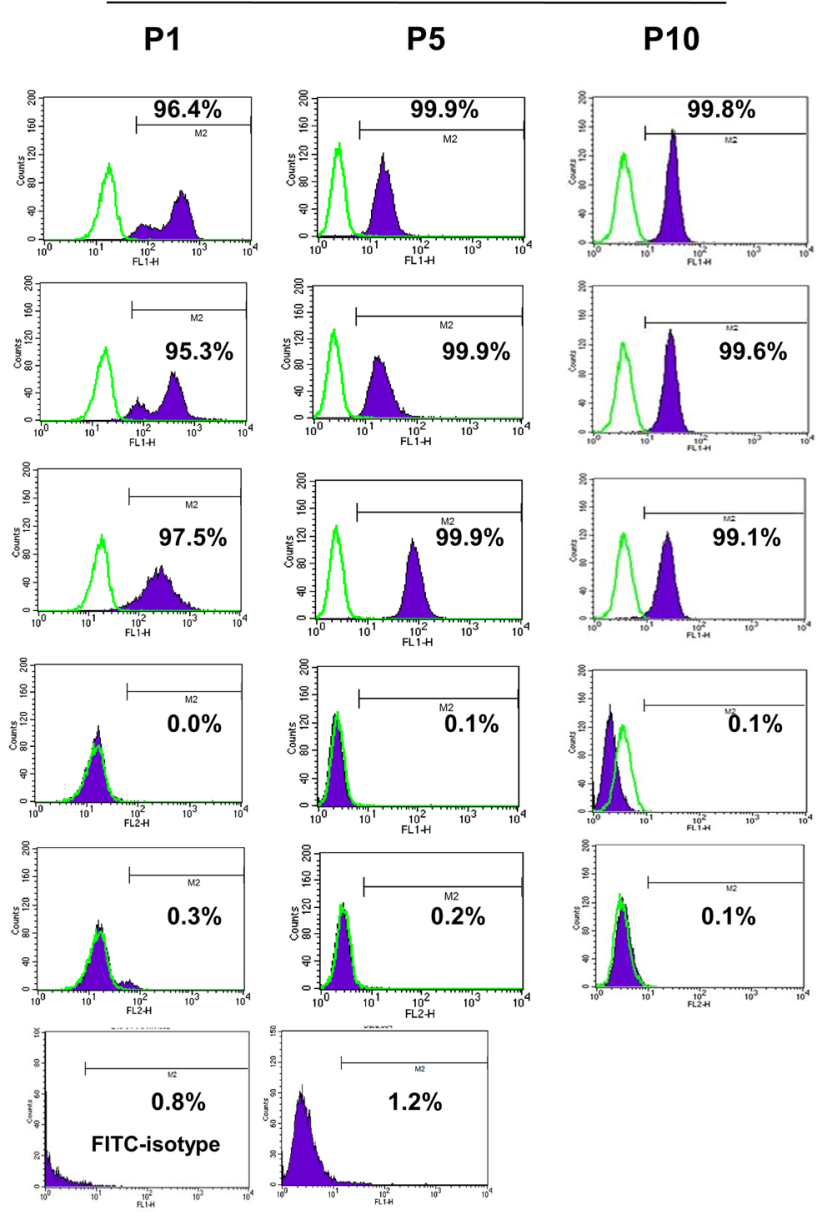

Fig. 3 Flow cytometric analyses of rFCPCs of E12 and E15. rFCPCs at passages 1, 5, and 10 were strongly positive for CD29, CD73 and CD105, and negative for CD34 and CD45 in both E12 and E15

expressed consistently during the 3 weeks of cardiomyogenic differentiation regardless of the groups including the control group. In contrast, genes of cardiac myosin heavy chain $(\alpha-$ MHC) and cardiac troponin T (cTnT) were not expressed in control cells. E12 rFCPCs showed that gene expression of MHC was detected at 2 weeks in all groups and these expressions were significantly increased at 3 weeks. The gene expression of E15 rFCPCs increased gradually over the 3 weeks of differentiation in all groups. For cTnT, gene expression was detected at 1 week and markedly increased over 3 weeks of differentiation in both E12 and E15 cells.

Cardiac differentiation was examined by immunocytochemical analyses using specific antibodies against cardiac alpha-myosin heavy chain ( $\alpha$-MHC) and connexin 43 (Cx43). MHC is a cardiac specific marker for myosin alpha and beta heavy chain $[19,27]$. Cx43 is the main constituent of the cardiomyocyte gap junction and for cardiomyocyte mitochondria [28] and Cx43 immunoreactivity was detected in cell membranes and also in the inner nuclear and plexiform layers [29]. At three weeks, a confocal picture showed that undifferentiated $\mathrm{rFCPCs}$ were almost negative against both anti-rat MHC and $\mathrm{Cx} 43$, whereas induced rFCPCs of all groups (D, T, and DT) were positive to both antibodies (Fig. 5B). Induced-rFCPCs at E15 showed higher expression levels of $\alpha$-MHC proteins than those of E12 in all groups of cardiomyogenic media. Also, induced-rFCPCs of the DT group at E12 and E15gave an intense staining with the antibodies against the $\alpha$-MHC compared to groups of D and T. The morphology of E12 and E15 rFCPCs gradually changed into a flat type and we could detect binucleated cells, one of cardiomyocytespecific cell types, at 3 weeks. Immunoblotting analyses showed that E12 and E15 rFCPC of the control group did not express proteins of $\alpha$-MHC and cardiac troponin $\mathrm{C}$ $(\mathrm{cTnC})$ but those proteins' expression increased in all groups of differentiation conditions (Fig. 5C). The protein expression of $\alpha$-MHC in induced-rFCPCs (D and DT 
group) at E15 was increased compared to E12 cells and expression of cTnC in induced-rFCPCs of E15 also increased in all groups but there was no statistical differences.

\section{Discussion}

Signaling pathways in cardiac progenitor cells are tightly regulated in early development and then organized heart tissue by dramatic morphological changes. Chamber formation starts at E10.5 and separation of atrial and ventricular myocardium starts at starts at E12.5 and is completed around E16.5 in rat. At this stage, a fourchamber heart is formed [23]. Therefore, fetal heart tissue at E12 and E15 corresponds to the chamber formation and septation stage, respectively. The developmental potential of progenitor cells by embryonic stage may affect their applicability in experimental and clinical operation depending on their properties. In this study, we characterized rat fetal cardiac progenitor cells of E12 and E15 from gestation and we examined their cardiomyogenic potential whether fetal cardiac progenitor cells were suitable for supporting therapeutic strategy.

Although both E12 and E15 rFCPCs differentiated into cardiomyotes-like cells expressing $\alpha$-MHC, connexin 43 ,
Fig. 5 Cardiomyogenic potential of rFCPCs of E12 and E15. A Gene expression patterns by RT-PCR. mRNA levels of alpha myosin heavy chain $(\alpha-\mathrm{MHC})$ and cTnT were measured in E12 and E15 rFCPCs by RT-PCR at 1, 2 and 3 weeks from cardiomyogenic differentiation using 5-azacytidine with dexamethasone $(D)$, TGF-b $(T)$ or both $(D T)$. B Densitometric analysis of RT-PCR. C \& D Immunostaining for $\alpha$ MHC (red) and Connexinx 43 (green) in differentiated rFCPCs of E12 and E15. DAPI staining for nucleus are shown in blue. Asterisks indicate the bi-nucleated cells. Scale bar $=50 \mathrm{um}$. E Immunoblotting analysis for $\alpha$-MHC and cardiac troponin $\mathrm{C}$ in differentiated rFCPCs of E12 and E15. Rat adult heart tissue was used as a positive control $(H)$. G Protein expression was analyzed by normalization using corresponding $\beta$-actin levels. Values represent the means \pm standard deviation and all experiments were repeated three times

and cTnC, E12 rFCPCs was a little inferior to E15 rFCPCs. Immunocytochemical studies suggested that $\mathrm{E} 15 \mathrm{rFCPCs}$ of all groups were strongly positive for $\alpha$-MHC compared to E12 rFCPCs groups. $\alpha$-MHC is a major protein comprising the thick filament in cardiac muscle and plays a major role in cardiac muscle contraction. Immunoblotting results also demonstrated that $\alpha$-MHC and cTnC expression level was increased at E15 groups compared to E12 cells. Stem cells exist plentifully in early fetal tissues but their number declines during development into neonatal and adult tissues. Stem cells are committed into lineage-specific progenitor/ precursor cells with a decrease in stemness and plasticity. Differences in cardiomyogenic potential were found in
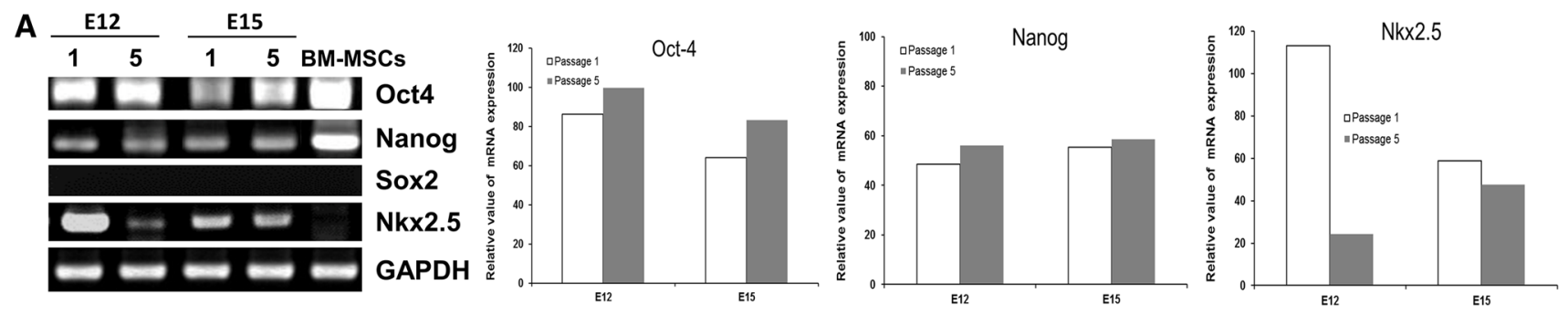

B
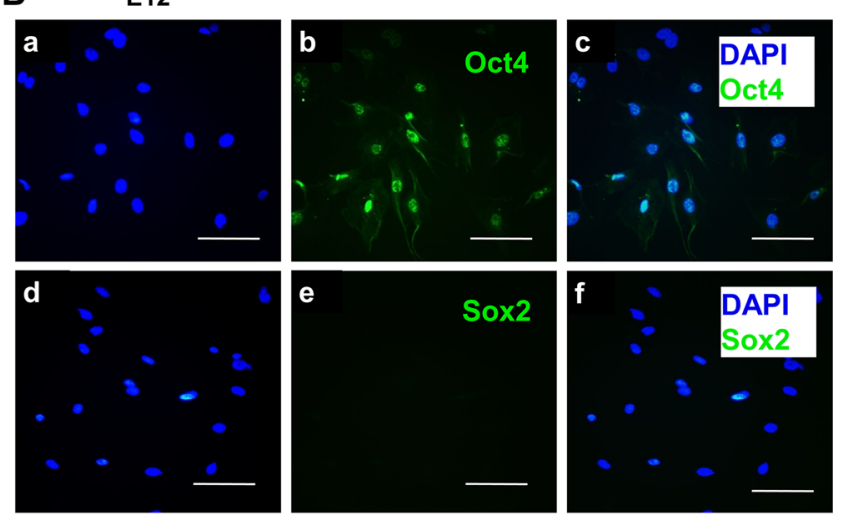

Fig. 4 Expression of embryonic stem cells (ESCs) markers in rFCPCs of E12 and E15. A rFCPCs expressed pluripotent markers, Oct4 and Nanog but not Sox 2 at passages 1 (P1) and 5 (P5) in RT-

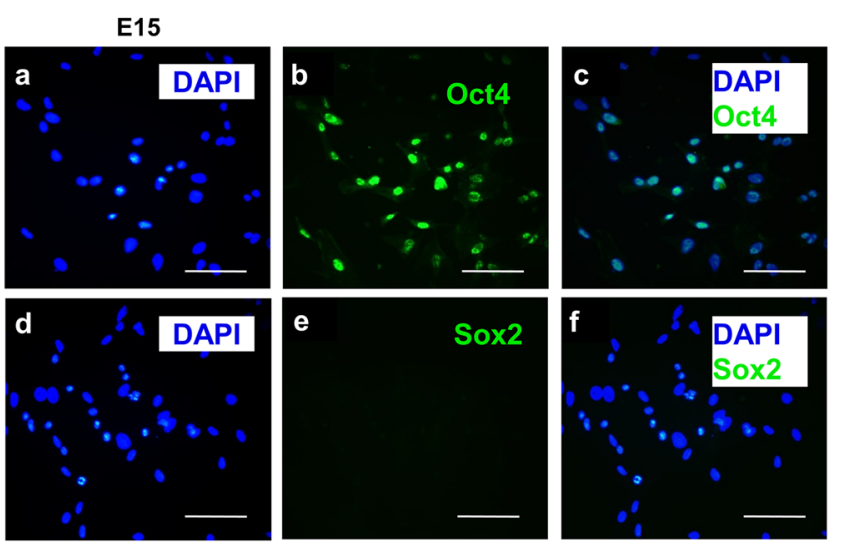

PCR analysis. B Oct4 and Sox2 was expressed in E12 and E15 rFCPCs passage 3 in immune-staining. Both cells of E12 and E15 expressed proteins Oct4. Scale bar $100 \mathrm{~mm}$ 
A

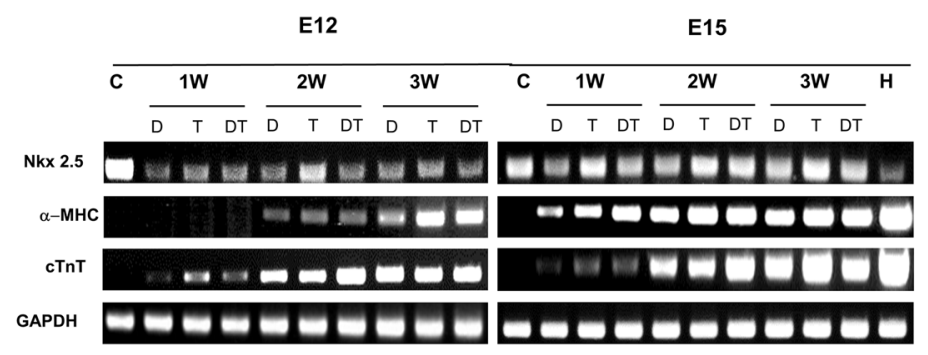

B
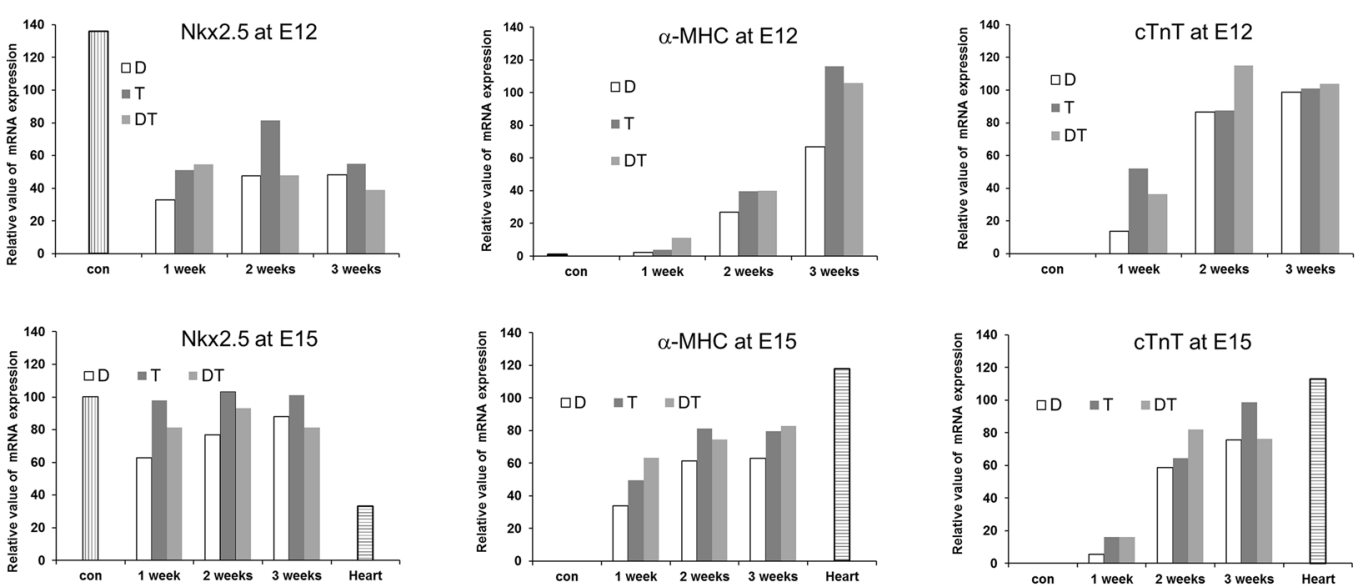

C

D
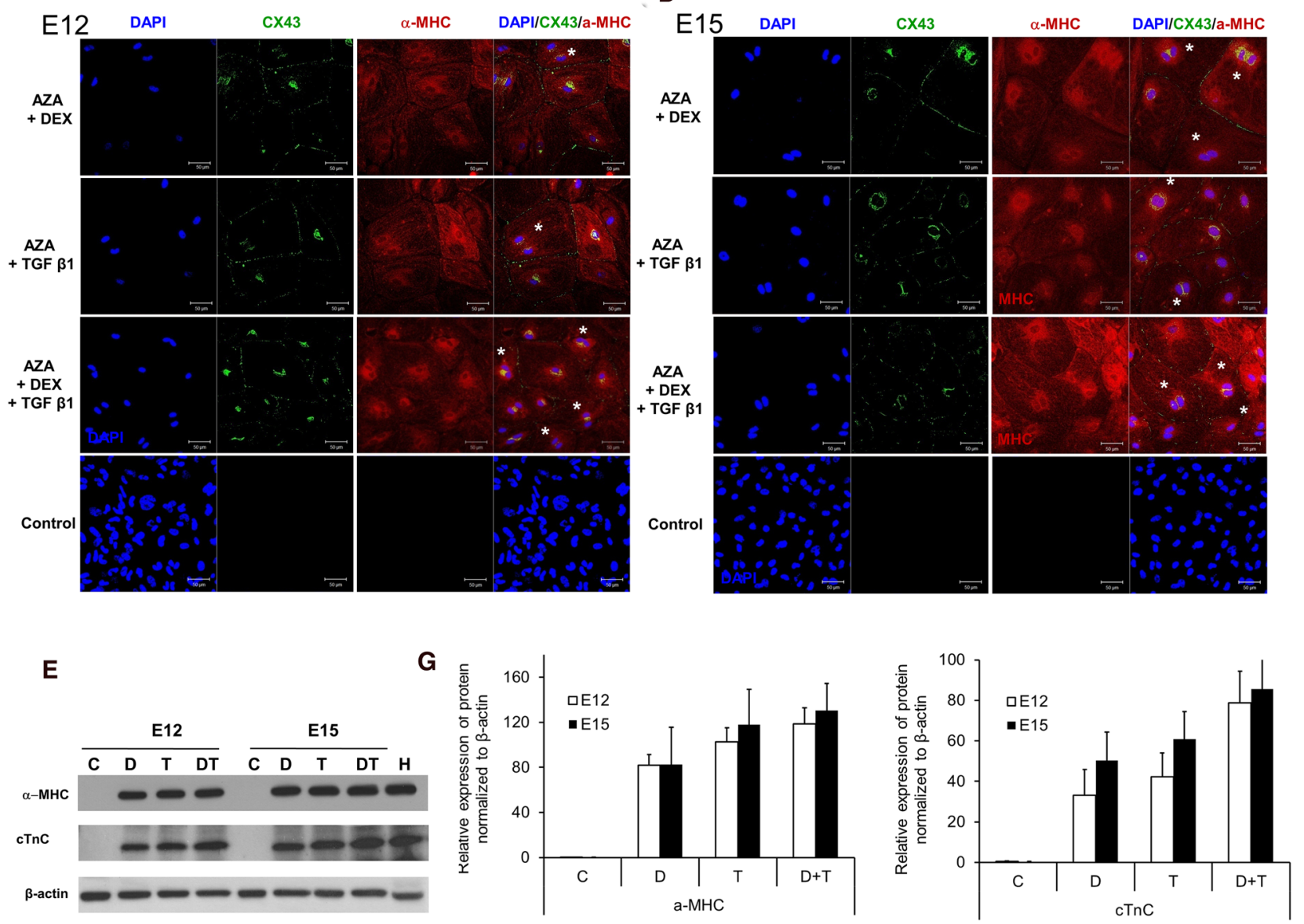
human fetal and adult progenitor cells. Human adult heartderived cardiomyocyte progenitor cells showed enhanced cardiomyogenic differentiation and smooth muscle cell formation compared to fetal cells in vitro [18]. Although our result suggests that E15 rFCPCs could be better in cariomyogenic differentiation than E12 rFCPCs, it is not clear if they can also differentiate into cardiac vascular cells thereby have more cardiogenic potential than E12 rFCPCs. Further studies will be also needed to determine if the differences in the differentiation ability between E12 and E15 rFCPCs in vitro will be reproducible in vivo.

At the cardiac crescent stage at E9 of rat, cardiac precursors irreversibly commit to cardiovascular lineages and begin to express transcription factor such as Nkx2.5 [11]. $\mathrm{Nkx} 2.5$, a murine homeobox gene, is expressed in early heart progenitor cells and their myogenic descendants [30] and is crucial in the induction of cardiogenesis by directly and indirectly activating further transcriptional factors like GATA4, myocyte enhancer factor 2C (MEF2C), T-box 5 (Tbx5) or heart and neural crest derivatives expressed transcript 1 (Hand1) [31]. Since it is strongly expressed in myogenic cells of the heart tube during cardiac development, $\mathrm{Nkx} 2.5$ can be used as a marker to identify a cardiac progenitor cell type and marks a cardiac progenitor cell population that possess the potential to differentiate into cardiomyocytes and conduction system cells [11, 32]. In previous study, cardiac progenitor cells expressing Nkx2.5 have been investigated in neonatal rodent hearts, however, the numbers of positive cells for Nkx2.5 decrease rapidly during post-natal period and they exist in adult hearts with rare cell population [33,34]. In our study, $\mathrm{rFCPCs}$ at E12 and E15 have not only primitive characteristics of expression Oct4 and Nanog but also cardiac characteristic expressing $\mathrm{Nkx} 2.5$, but three differentiated markers, $\alpha$-MHC, cTnT, and cTnC were not expressed during ex vivo expansion. These results indicate that rFCPCs at E12 and E15 represent cardiac progenitor cells as well as they have the properties of primitive stage. c-kit was a well-known hematopoietic marker stem cell marker but, in recent study, adult cardiac stem cells which displayed cardiac and endothelial commitment were isolated using c-kit [35]. Meanwhile, our rFCPCs did not appear to express c-kit (Fig. 3) and Sca-1 (data not shown) by FACS analysis. Similarly, cardiac stem cells expressing Isl1, Nkx2.5 and GATA-4 but not c-Kit or Sca-1 have been reported in E16 or neonatal rodent hearts [20, 33, 34] and Nkx2.5 positive cardiac progenitor cells isolated from human fetal heart tissue at 12 weeks of gestation did not appear to express c-kit [19]. It is, therefore, likely that our rFCPCs might be a primitive progenitor cell type distinct from the cardiac stem/progenitor cells in adult heart tissue.

The E12 rFCPCs expressed a high level of Oct 4 compared to E15 until passage 5 and showed a steep decline of Nkx2.5 expression at passage 5 (we investigated the expression of examined genes until passage 5). However, Nkx2.5 expression at E15 was maintained until passage 5 and Oct 4 expression slightly increased at passage 5 . We also detected an intense staining for Oct4 antibody in E12 heart tissue section. Average doubling time of E12 rFCPCs from passage 3 to passage 15 was about 5 hours longer than E15. In our previous study, rat fetal cartilage progenitor cells at E14 had much lower proliferation capacity and chondrogenic potencial than E16 and E20 cells and only these cells expressed Oct4, Sox2, Nanog [36]. Colony forming ability of E15 was a little better than E12, however, there was no statistical differences. These results may suggest that E12 rFCPCs are in a primitive state compared to E15 cells, whereas the E15 rFCPCs are committed a little more into cardiomyogenic progenitor cells.

Our rFCPCs expressed the ESCs markers, Oct4 and Nanog except for Sox2. Our results on ESCs-like characteristics of rFCPCs were similar to results of previous reports. Stem cell populations were isolated from many fetal tissues such as blood, liver, and bone marrow. They expressed ESCs markers, Oct4 and Nanog, and showed a long-term expansion potential $[12,13]$. In another report, human fetal stem cells were isolated from the heart, liver, lung, derma, muscle, kidney, adipose tissue, and amniotic fluid [37]. Those cells did not expressed Nanog, but persistently expressed Oct 4 even after more than 40 population doublings [38]. In rodents, fetal cardiac MSCs at E16 expressed embryonic markers, Oct4, Nanog, and Sox2 $[21,22]$. In this study, we could find moderate staining for Sox 2 protein on fetal heart tissue of E12 using immunohistochemistry but isolated rFCPCs from E12 and E15 fetus did not express Sox 2 gene and protein during ex vivo expansion. In mouse ESCs, Oct4, Sox2, and Nanog cooperatively maintain pluripotency together through a tightly regulated transcriptional loop [39, 40]. However, new functions has recently emerged with these transcription factors in the process of cell lineage commitment. Oct4 expression endows hESCs with the capacity to form mesoderm, whereas Sox 2 is essential for ectoderm differentiation and Nanog is imperative for definitive endoderm generation [41-43]. During embryonic development, cardiac mesoderm is the origin of fetal cardiac progenitor cells (CPCs). Therefore, E12 heart tissue at more primitive stages showed moderate staining for Sox 2 and this expression decreased in E15 heart tissue on relatively committed states into CPCs. rFCPCs of E12 and E15 expressing Oct4 and Nanog also showed null expression for Sox 2 ex vivo expansion. These results suggest that the cardiac lineage commitment from pluripotency state to CPCs may begin by the breaking of a tightly regulated transcriptional loop such as a Sox 2 decline.

Cytokine mixture also seems to contribute to efficient differentiation of the rFCPCs. Five-azacytidine, a DNA 
demethylating agent, known to enhance cardiac differentiation [26]. Dexamethasone has been reported to promote sarcomeric myosin and cardiac myosin heavy chain expression in adult stem cells and ESCs [26]. TGF- $\beta 1$ resulted in a highly significant improvement in efficiency and cultures almost entirely composed of mature cardiomyocytes [27]. We found that a combination of all three compounds was optimal to enable the differentiation of rFCPCs into cardiomyocytes, yet we could not detect beating cells, fully differentiated cardiomyocytes. Zhang et al. reported that $\mathrm{Nkx} 2.5$ positive CPCs derived from embryonic heart tubes of human and rat could differentiate into cardiac pacemaking cells after the cell being treated with endothelin-1 [44]. Collectively, unique properties of rFCPCs and combination of selected cytokines might cooperatively work, resulting in the efficient differentiation of rFCPCs into cardiomyocytes in vitro. Further studies may be needed for the best optimal differentiation into functionally complete cardiomyocytes.

In general, MSCs showed fibroblast like morphology with a spindle shape [45]. In our study, the morphology of rFCPCs were similar to those of MSCs. rFCPCs also exhibited some of the characteristics typical of MSCs in terms of expression of CD105, CD73 and CD29, and null expression of CD34 and CD45. In previous studies, human fetal heart-derived adherent cells were positive for the antigens of CD73, CD105, CD29, CD44, CD166, CD86, and HLA-ABC, and negative for CD45, CD34 and HLADR [19, 46]. Fang et al. [38] reported that human fetal heart stem cells express CD44 and Flk2, yet, are negative for CD34, CD45, and HLA-DR. However, little is reported regarding rodent fetal heart-derived cells. Recently, cardiac MSCs were isolated from rat fetal hearts at 16 days of gestation and they were positive for CD29, CD44, CD73, CD90, and CD105 and negative for CD31, CD45, and HLA-DR [21]. In this study, we could not discriminate the major differences in surface antigen expression and morphological appearance between E12 and E15. However, despite these similarities on surface markers mentioned above, significant differences between rFCPCs and BMMSCs were examined at the molecular level like the expression of $\mathrm{Nkx} 2.5$, a cardiac specific transcription factor, only in rFCPCs. In another report, although human cardiac stromal cells and MSCs exhibited a similar surface marker profile, they showed remarkably different profiles in their genes, microRNAs, and protein expression [47]. Biologically, cardiac stromal cells, when compared to BMMSCs, were less competent in acquiring the adipogenic and osteogenic phenotypes but more efficient in cardiovascular differentiation. In this study, rFCPCs showed fibroblast like morphology with a spindle shape like as BM-MSCs, but we did not compare their properties of rFCPCs with those of fibroblasts directly. Previously, human BM-MSCs were reported to show a broad structural and functional overlap with dermal fibroblasts [48], therefore, it is difficult to clearly distinguish between fibroblasts and stem/progenitor cells of bone marrow or cardiac origin using surface markers. In another study, human dermal fibroblasts displayed similar phenotypic and differentiation capacities to fat-derived MSCs, however, differed in anti-inflammatory and angiogenic potentials [49].

In our study, we have identified rat cardiac progenitor cells in fetal heart which have the characteristics of embryonic markers and a cardiomyogenic transcription signature and could be differentiated into cardiomyocytes. The properties of fetal cardiac progenitor cells are changeable during development. Oct4 expression was strong and stable in E12 rFCPCs, while E15 rFCPCs exhibited stable and intense expression of the Nkx2.5 gene. Although E12 cells are developmental early stage, cardiomyogenic potential is a little better in E15 rFCPCs than E12 rFCPCs. rFCPCs from E12 and E15 approximately correspond to those in humans around embryo days $28-50$ and after and beyond embryo day 60 . We speculate that our results provides important information about stem cell biology in the heart and their possible use as a cell-based therapy for cardiac regeneration. Therefore, further studies are necessary to understand the exact different potential with the developmental stage and to examine their therapeutic value which will be supported using animal models.

Acknowledgements This research was supported by Inha University Research Grant.

\section{Compliance with ethical standards}

Conflict of interest Tung Nguyen Thanh, Him Cha Shin, Hwal Ran Kim, So Ra Park, Jiyoung Kim, and Byung Hyune Choi declare that they have no conflict of interest.

Ethical statement All animals used in this study were treated in accordance with the INHA University Institutional Animal Care and Use Committee (INHA-IACUC approval number: 121120-168).

\section{References}

1. Matar AA, Chong JJ. Stem cell therapy for cardiac dysfunction. Springerplus. 2014;3:440.

2. Kuhn EN, Wu SM. Origin of cardiac progenitor cells in the developing and postnatal heart. J Cell Physiol. 2010;225:321-5.

3. Lunde K, Solheim S, Aakhus S, Arnesen H, Abdelnoor M, Egeland $\mathrm{T}$, et al. Intracoronary injection of mononuclear bone marrow cells in acute myocardial infarction. $\mathrm{N}$ Engl $\mathrm{J}$ Med. 2006;355:1199-209.

4. Schächinger V, Erbs S, Elsässer A, Haberbosch W, Hambrecht R, Hölschermann $\mathrm{H}$, et al. Improved clinical outcome after intracoronary administration of bone-marrowderived progenitor cells in acute myocardial infarction: final 1-year results of the REPAIR-At55MI trial. Eur Heart J. 2006;27:2775-83. 
5. Rose RA, Jiang H, Wang X, Helke S, Tsoporis JN, Gong N, et al. Bone marrow-derived mesenchymal stromal cells express cardiac-specific markers, retain the stromal phenotype, and do not become functional cardiomyocytes in vitro. Stem Cells. 2008;26:2884-92.

6. Chien KR. Stem cells: lost in translation. Nature. 2004;428:607-8.

7. Beltrami AP, Barlucchi L, Torella D, Baker M, Limana F, Chimenti $\mathrm{S}$, et al. Adult cardiac stem cells are multipotent and support myocardial regeneration. Cell. 2003;114:763-76.

8. Nadal-Ginard B, Kajstura J, Leri A, Anversa P. Myocyte death, growth, and regeneration in cardiac hypertrophy and failure. Circ Res. 2003;92:139-50.

9. Chong JJ, Chandrakanthan V, Xaymardan M, Asli NS, Li J, Ahmed I, et al. Adult cardiac-resident MSC-like stem cells with a proepicardial origin. Cell Stem Cell. 2011;9:527-40.

10. Laugwitz KL, Moretti A, Lam J, Gruber P, Chen Y, Woodard S, et al. Postnatal isl1 + cardioblasts enter fully differentiated cardiomyocyte lineages. Nature. 2005;433:647-53.

11. Wu SM, Fujiwara Y, Cibulsky SM, Clapham DE, Lien CL, Schultheiss TM, et al. Developmental origin of a bipotential myocardial and smooth muscle cell precursor in the mammalian heart. Cell. 2006;127:1137-50.

12. Abdulrazzak H, Moschidou D, Jones G, Guillot PV. Biological characteristics of stem cells from foetal, cord blood and extraembryonic tissues. J R Soc Interface. 2010;Suppl. 6:S689-706.

13. Guillot PV, Gotherstrom C, Chan J, Kurata H, Fisk NM. Human first-trimester fetal MSC express pluripotency markers and grow faster and have longer telomeres than adult MSC. Stem Cells. 2007;25:646-54.

14. Montjovent MO, Bocelli-Tyndall C, Scaletta C, Scherberich A, Mark S, Martin I, et al. In vitro characterization of immunerelated properties of human fetal bone cells for potential tissue engineering applications. Tissue Eng Part A. 2009;15:1523-32.

15. Götherström C, Ringdén O, Tammik C, Zetterberg E, Westgren $\mathrm{M}$, Le Blanc K. Immunologic properties of human fetal mesenchymal stem cells. Am J Obstet Gynecol. 2004;190:239-45.

16. Campagnoli C, Roberts IA, Kumar S, Bennett PR, Bellantuono I, Fisk NM. Identification of mesenchymal stem/progenitor cells in human first-trimester fetal blood. liver, and bone marrow. Blood. 2001;98:2396-402.

17. Fan CG, Tang FW, Zhang QJ, Lu SH, Liu HY, Zhao ZM. Characterization and neural differentiation of fetal lung mesenchymal stem cells. Cell Transplantaion. 2005;14:311-21.

18. van Vliet P, Smits AM, de Boer TP, Korfage TH, Metz CH, Roccio M. Foetal and adult cardiomyocyte progenitor cells have different developmental potential. J Cell Mol Med. 2010;14: 861-70.

19. Gonzales C, Ullrich ND, Gerber S, Berthonneche C, Niggli E, Pedrazzini T. Isolation of cardiovascular precursor cells from the human fetal heart. Tissue Eng Part A. 2012;18:198-207.

20. Srikanth GVN, Tripathy NK, Nityanand S. Isolation and characterization of cardiac MSCs from rat foetal hearts. Int J Reg Med. 2012;1:1-8.

21. Srikanth GVN, Tripathy NK, Nityanand S. Fetal cardiac mesenchymal stem cells express embryonal markers and exhibit differentiation into cells of all three germ layers. World J Stem Cells. 2013;5:26-33.

22. Rubart M, Pasumarthi KB, Nakajima H, Soonpaa MH, Nakajima HO, Field LJ. Physiological coupling of donor and host cardiomyocytes after cellular transplantation. Circ Res. 2003;92: 1217-24.

23. Bruneau BG. The developmental genetics of congenital heart disease. Nature. 2008;451:943-8.

24. Buckingham M, Meilhac S, Zaffran S. Building the mammalian heart from two sources of myocardial cells. Nat Rev Genet. 2005;6:826-35.
25. Cristofalo VJ, Allen RG, Pignolo RJ, Martin BG, Beck JC. Relationship between donor age and the replicative lifespan of human cells in culture: a reevaluation reevaluation. Proc Natl Acad Sci U S A. 1998;95:10614-9.

26. Takahashi T, Lord B, Schulze PC, Fryer RM, Sarang SS, Gullans $\mathrm{SR}$, et al. Ascorbic acid enhances differentiation of embryonic stem cells into cardiac myocytes. Circulation. 2003;107:1912-6.

27. Goumans MJ, de Boer TP, Smits AM, van Laake LW, van Vliet $\mathrm{P}$, Metz $\mathrm{CH}$, et al. TGF-beta1 induces efficient differentiation of human cardiomyocyte progenitor cells into functional cardiomyocytes in vitro. Stem Cell Res. 2007;1:138-49.

28. Boengler K, Konietzka I, Buechert A, Heinen Y, Garcia-Dorado $\mathrm{D}$, Heusch $\mathrm{G}$, et al. Loss of ischemic preconditioning's cardioprotection in aged mouse hearts is associated with reduced gap junctional and mitochondrial levels of connexin 43. American Journal of Physiology - Heart and Circulatory Physiology. 2006;292:1764-9.

29. Kerr NM, Johnson CS, de Souza CF, Chee KS, Good WR, Green $\mathrm{CR}$, et al. Immunolocalization of Gap Junction Protein Connexin43 (GJA1) in the Human Retina and Optic Nerve. Invest Ophthalmol Vis Sci. 2010;51:4028-34.

30. Komuro I, Izumo S. Csx: a murine homeobox-containing gene specifically expressed in the developing heart. Proc Natl Acad Sci USA. 1993;90:8145-9.

31. Tanaka M, Chen Z, Bartunkova S, Yamasaki N, Izumo S. The cardiac homeobox gene Csx/Nkx2.5 lies genetically upstream of multiple genes essential for heart development. Development. 1999;126:1269-80.

32. Hidaka K, Lee JK, Kim HS, Ihm CH, Iio A, Ogawa M, et al. Chamber-specific differentiation of Nkx2.5-positive cardiac precursor cells from murine embryonic stem cells. FASEB J. 2003;17:740-2.

33. Milgrom-Hoffman M, Harrelson Z, Ferrara N, Zelzer E, Evans $\mathrm{SM}$, Tzahor E. The heart endocardium is derived from vascular endothelial progenitors. Development. 2011;138:4777-87.

34. Misfeldt AM, Boyle SC, Tompkins KL, Bautch VL, Labosky PA, Baldwin HS. Endocardial cells are a distinct endothelial lineage derived from Flk1+ multipotent cardiovascular progenitors. Dev Biol. 2009;333:78-89.

35. Sandstedt J, Jonsson M, Dellgren G, Lindahl A, Jeppsson A, Asp J. Human C-kit + CD45- cardiac stem cells are heterogeneous and display both cardiac and endothelial commitment by singlecell qPCR analysis. Biochem Biophys Res Commun. 2014;443: 234-8.

36. Kim M, Kim JY, Park SR, Park DY, Kim YJ, Choi BH, et al. Comparison of Fetal Cartilage-Derived Progenitor Cells Isolated at Different Developmental Stages in a Rat Model. Dev Growth Differ. 2016;58:167-79.

37. Huh MI, Kim MS, Kim HK, Lim JO. Effect of Conditioned Media Collected from Human Amniotic Fluid-Derived Stem Cells (hAFSCs) on Skin Regeneration and Photo-aging. Tissue Engineering and Regenerative Medicine. 2014;11:171-7.

38. Fang B, Li N, Song Y, Lin Q, Zhao RC. Comparison of human post-embryonic, multipotent stem cells derived from various tissues. Biotechnol Lett. 2009;31:929-38.

39. Loh YH, Wu Q, Chew JL, Vega VB, Zhang W, Chen X, et al. The Oct4 and Nanog transcription network regulates pluripotency in mouse embryonic stem cells. Nat Genet. 2006;38:431-40.

40. Niwa H. How is pluripotency determined and maintained? Development. 2007;134:635-46.

41. Teo AK, Arnold SJ, Trotter MW, Brown S, Ang LT, Chng Z, et al. Pluripotency factors regulate definitive endoderm specification through eomesodermin. Genes Dev. 2011;25:238-50.

42. Wang Z, Oron E, Nelson B, Razis S, Ivanova N. Distinct lineage specification roles for NANOG, OCT4, and SOX2 in human embryonic stem cells. Cell Stem Cell. 2012;10:440-54. 
43. Loh KM, Lim B, Ang LT. Ex uno plures: molecular designs for embryonic pluripotency. Physiol Rev. 2015;95:245-95.

44. Zhang X, Zhang CS, Liu YC, Yang XQ, Xiong SH, Wen Y, et al. Isolation, culture and characterization of cardiac progenitor cells derived from human embryonic heart tubes. Cells Tissues Organs. 2009;190:194-208.

45. Miao Z, Jin J, Chen L, Zhu J, Huang W, Zhao J, et al. Isolation of mesenchymal stem cells from human placenta: comparison with human bone marrow mesenchymal stem cells. Cell Biol Int. 2006;30:681-7.

46. Jiang XX, Su YF, Li XS, Zhang Y, Wu Y, Mao N. Human fetal heart-derived adherent cells with characteristics similar to mesenchymal progenitor cells. Zhongguo Shi Yan Xue Ye Xue Za Zhi. 2006;14:1191-4.
47. Rossini A, Frati C, Lagrasta C, Graiani G, Scopece A, Cavalli S, et al. Human cardiac and bone marrow stromal cells exhibit distinctive properties related to their origin. Cardiovasc Res. 2011;89:650-60.

48. Haniffa MA, Wang XN, Holtick U, et al. Adult human fibroblasts are potent immunoregulatory cells and functionally equivalent to mesenchymal stem cells. J Immunol. 2007;179:1595.

49. Blasi A, Martino C, Balducci L, Saldarelli M, Soleti A, Navone SE, et al. Dermal fibroblasts display similar phenotypic and differentiation capacity to fat-derived mesenchymal stem cells, but differ in anti-inflammatory and angiogenic potential. Vasc Cell. 2011;8:5. 